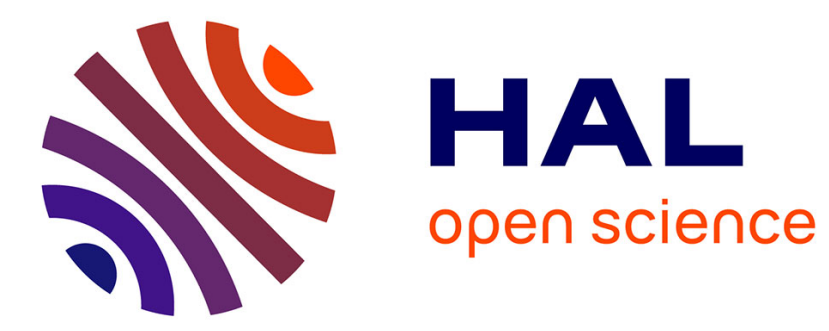

\title{
3D localization and tracking of gold particles in biological environment using digital holography
}

\author{
F. Verpillat, P. Desbiolles, Michel Gross
}

\section{To cite this version:}

F. Verpillat, P. Desbiolles, Michel Gross. 3D localization and tracking of gold particles in biological environment using digital holography. Biomedical Optics, Optical Society of America, Apr 2012, Miami, United States. pp.BSu3A.62. hal-01927543

\section{HAL Id: hal-01927543 \\ https://hal.science/hal-01927543}

Submitted on 19 Nov 2018

HAL is a multi-disciplinary open access archive for the deposit and dissemination of scientific research documents, whether they are published or not. The documents may come from teaching and research institutions in France or abroad, or from public or private research centers.
L'archive ouverte pluridisciplinaire HAL, est destinée au dépôt et à la diffusion de documents scientifiques de niveau recherche, publiés ou non, émanant des établissements d'enseignement et de recherche français ou étrangers, des laboratoires publics ou privés. 


\title{
3D localization and tracking of gold particles in biological environment using digital holography.
}

\author{
F. Verpillat ${ }^{1}$, P. Desbiolles ${ }^{1}$, and M. Gross ${ }^{2}$ \\ ${ }^{1}$ Laboratoire Kastler Brossel, ENS, UPMC-Paris6, CNRS UMR 8552, Paris, 75005, France \\ 2 Laboratoire Charles Coulomb, CNRS UMR 5221, Université Montpellier II, Montpellier, 34095, France \\ michel.gross@univ-montp2.fr
}

\begin{abstract}
By using the dark field holographic microscopy technique described in Opt. Express, 19 pp 26044-26055 (2011) we have track gold particles in brownian motion in living cells. First results are presented. The particles remain confined to a region a few microns in size. We interpret this as a cage effect related to the cell structure.
\end{abstract}

(C) 2013 Optical Society of America

OCIS codes: (090.1995) Digital holography; (090.1760) Computer holography; (100.4999) Pattern recognition, target tracking; (180.0180) Microscopy; (290.5850) Scattering, particles.

Citation M. Gross, F. Verpillat, and P. Desbiolles, "3D localization and tracking of gold particles in biological environment using digital holography," in Biomedical Optics, OSA Technical Digest (Optical Society of America, 2012), paper BSu3A.62.

Conference Paper

Biomedical Optics

Miami, Florida

April 28, 2012

http://www.opticsinfobase.org/abstract.cfm?URI=BIOMED-2012-BSu3A. 62

\section{Introduction}

The study of cellular processes at the single-molecule level is a flourishing field of research in Biology. Individual molecules labeled with sub-micron markers can now be tracked in a cellular environment, and quantitative information about their dynamics can be obtained by reconstructing their trajectory. One of the most used techniques for this purpose is single-molecule fluorescence microscopy (SMFM), but standard SMFM provides no information on the axial position of the marker, limiting this technique to 2D tracking. Digital Holographic Microscopy (DHM) [1] of gold nano particles circumvents this drawback. Moreover gold nano particles are not toxic for cells, and can be used as markers in biology [2]. As the scattering cross section of a particle scales as the sixth power of its radius [3], how easily and accurately a particle can be detected strongly depends on its size. Micron-sized colloids or particles can be easily detected by DHM in transmission geometry [4] or by In Line Holography [5], which is able to localize and track in 3D micron-sized latex particles with nanometer accuracy [6].

Since the signal is more than three orders of magnitude lower, Nano particles detection requires DHM with dark field illumination scheme. Atlan et al. [7] and Warnasooriya et al. [8] uses for example Total Internal Reflection (TIR) on a prism to detect and localize $d=50 \mathrm{~nm}$ and $d=40 \mathrm{~nm}$ particles, which are respectively spin coated on glass slide or attached to a cell membrane. The Atlan and Warnasooriya TIR configuration does not allow to track moving particles, since it yields a standing wave: when a moving particle crosses a node, the illumination (and thus the signal) goes down to zero, and the tracked particle is lost. More recently, Verpillat et al., which use a standing wave free dark field illumination scheme, localize and track $d=100 \mathrm{~nm}$ particles in brownian motion in water [9].

By using the Verpillat method, we have track gold particles within HeLa cells. We present here our first results. The particle diameter is $d=50 \mathrm{~nm}$, and the random motion of the particle remains confined to a region a few microns in size. We interpret this as a cage effect related to the cell cytoskeleton.

\section{Digital holography setup}

The DHM setup is shown on Fig. 1. The motion of $d=50 \mathrm{~nm}$ gold particles in HeLa cells is investigated. The particles are brought into the cell by Pinocytosis $[10,11]$ with initial particles concentration $10^{-9} \mathrm{~m} / \mathrm{l}$. The laser (Crystal Laser: 


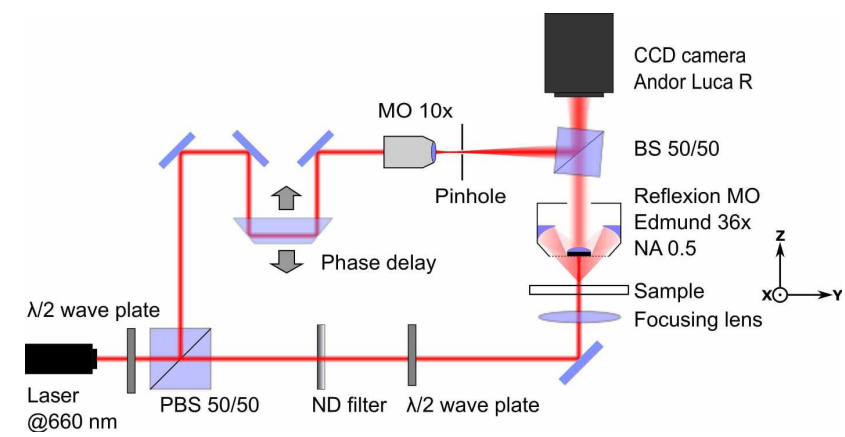

Fig. 1. Experimental setup. The sample is located in the $\mathrm{X}, \mathrm{Y}$ plane. $\mathrm{Z}$ is the optical axis of the microscope objective.
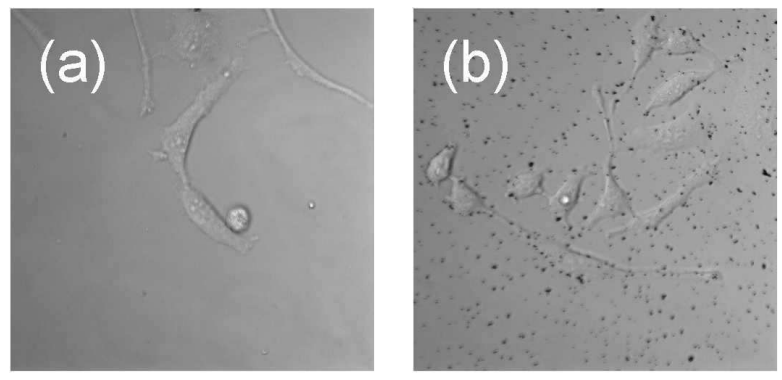

Fig. 2. White light images of HeLa cells without (a) and with (b) particles.

Diode Pump Solid State laser, $660 \mathrm{~nm}, 0.6 \mathrm{~mm}$ coherence length) is split into two beams by a Polarizing Beam Splitter (PBS), a half-wave plate PBS setting the beams energy ratio. The reference beam passes through a dove prism fixed on a micrometer translation stage to adjust the length of the optical path. It is spatially filtered through a $35 \mu \mathrm{m}$ diameter pinhole and expanded as to uniformly cover the CCD chip of the camera (Andor Luca R: $512 \times 512$ pixels, $22.5 \mathrm{~Hz}$ ). The illumination beam is focalized on the sample (waist diameter $200 \mu \mathrm{m}, 250 \mathrm{~W} / \mathrm{cm}^{2}$ ). The light scattered by the particles is collected in transmission with a dark-field reflecting objective (Edmund Optics; ReflX series: NA=0.5, $36 \times$ ). A small mask on the input of the objective limits the collection of light between NA=0.2 and NA=0.5, so the illumination beam is totally blocked after passing through the sample. This dark-field configuration prevents the saturation of the CCD chip. Since the illumination is along the optical axis $z$, standing waves are minimized. A nonpolarizing 50/50 beam splitter (BS) behind the objective combines the scattered light with the reference beam. BS is tilted by few degrees to be in off-axis holographic configuration.

\section{Results and conclusion}

Figure 2 shows the results we have obtained. The details of the holographic reconstruction, localization and tracking calculations are given in [9]. Figure $2(a, b)$ show white light images of HeLa cells without and with gold particles. The particles are labeled with streptavidin, and many particles aggregates. Most of the black points of Fig.2 (b) correspond thus to aggregates, which are attached to the sample coverslip. Figure 3 (a) shows an holographic reconstructed images of the sample displayed in arbitrary log scale for the optical field intensity. Most of the bright point corresponds to particles or aggregates attached to the coverslip. They do not move. Some of the bright point like the one marked by the withe arrow move slightly. They correspond particles in motion within the cell. We have track the particle marked by the arrow, and we have plot its 3D motion on Fig.3 (b). Since there is no standing waves, the particles can be tracked 

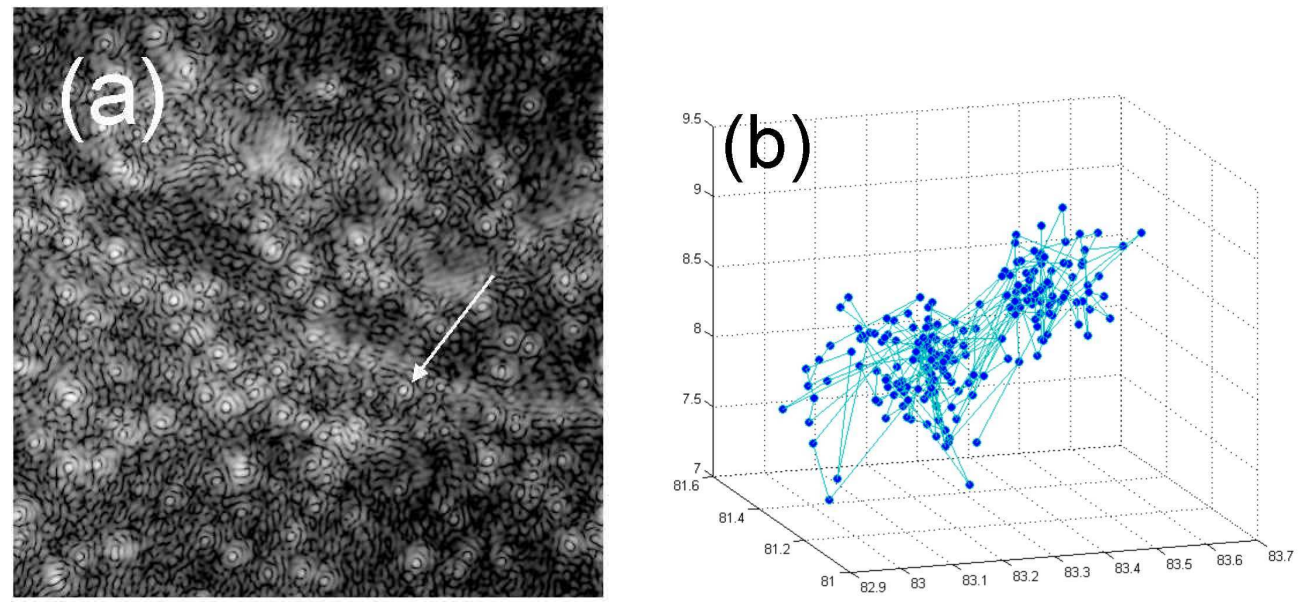

Fig. 3. Reconstructed holographic images of HeLa cells with $d=50 \mathrm{~nm}$ gold particles (a). Plot of the 3D motion of the particle marked by the white arrow (b). $\mathrm{x}, \mathrm{y}$ and $\mathrm{z}$ coordinates are in $\mu \mathrm{m}$ Units.

for long sequences of images (400 images or steps). For clarity, we have displayed only 200 steps of the motion on Fig.3 (b).

As it can be seen, the particle in motion remains located in confined region of the 3D space. We interpret this as a cage effect related to the cell cytoskeleton. I could be interesting to analyze in detail this effect, which should depends on the particle diameter. This preliminary work shows that is possible to track $d=50 \mathrm{~nm}$ gold nanoparticules in brownian diffusion motion within a biological sample, and to get by the way biological information.

\section{References}

1. U. Schnars and W. Jüptner. Direct recording of holograms by a ccd target and numerical reconstruction. Applied Optics, 33(2):179-181, 1994.

2. L. Cognet, C. Tardin, D. Boyer, D. Choquet, P. Tamarat, and B. Lounis. Single metallic nanoparticle imaging for protein detection in cells. Proceedings of the National Academy of Sciences, 100(20):11350, 2003.

3. H.C. Hulst and HC Van De Hulst. Light scattering by small particles. Dovers Publications Inc., 1957.

4. P. Marquet, B. Rappaz, P.J. Magistretti, E. Cuche, Y. Emery, T. Colomb, and C. Depeursinge. Digital holographic microscopy: a noninvasive contrast imaging technique allowing quantitative visualization of living cells with subwavelength axial accuracy. Optics letters, 30(5):468-470, 2005.

5. W. Xu, MH Jericho, IA Meinertzhagen, and HJ Kreuzer. Digital in-line holography for biological applications. Proceedings of the National Academy of Sciences, 98(20):11301, 2001.

6. F.C. Cheong, S. Duarte, S.H. Lee, and D.G. Grier. Holographic microrheology of polysaccharides from streptococcus mutans biofilms. Rheologica Acta, 48(1):109-115, 2009.

7. M. Atlan, M. Gross, P. Desbiolles, E. Absil, G. Tessier, and M. Coppey-Moisan. Heterodyne holographic microscopy of gold particles. Optics letters, 33(5):500-502, 2008.

8. N. Warnasooriya, F. Joud, P. Bun, G. Tessier, M. Coppey-Moisan, P. Desbiolles, M. Atlan, M. Abboud, and M. Gross. Imaging gold nanoparticles in living cell environments using heterodyne digital holographic microscopy. Optics Express, 18(4):3264-3273, 2010. 
9. F. Verpillat, F. Joud, P. Desbiolles, and M. Gross. Dark-field digital holographic microscopy for 3d-tracking of gold nanoparticles. Optics Express, 19(27):26044-26055, 2011.

10. C.Y. Okada and M. Rechsteiner. Introduction of macromolecules into cultured mammalian cells by osmotic lysis of pinocytic vesicles. Cell, 29(1):33-41, 1982.

11. R.D. Park, P.C. Sullivan, and B. Storrie. Hypertonic sucrose inhibition of endocytic transport suggests multiple early endocytic compartments. Journal of cellular physiology, 135(3):443-450, 1988. 